\title{
QUICKSAND IN THE CONTRACT GROUND
}

(Received 20 July, 1982)

In his book, The Grounds of Moral Judgment, ${ }^{1}$ Russell Grice argues for what shall be called 'the contract ground thesis' (CGT):

It is in the interest of every member of some group to make a contract with every other member to do actions of class $\boldsymbol{X}$ (The Contract Ground),

strictly implies

Every member of that group has an abstract obligation and a reason to do actions of class $X .^{2}$

This thesis, the keystone of Grice's contractualism, has been attacked by Jesse Kalin ${ }^{3}$ and subsequently defended by Grice. ${ }^{4}$ Following a very brief review of Kalin's criticism and Grice's reply, we shall show that the defense fails - the Contract Ground Thesis is without justification.

\section{KALIN'S COUNTEREXAMPLE}

In 'Grice's contract ground and moral obligation: the inadequacy of contractualism', Kalin offers the following counterexample to CGT. Suppose there is a bowling club which normally meets at $8: 00$. This meeting time was established by mutual consent of the members as were the fines imposed in the event of absences. Suppose further that there is a widely recognized advantage, which accrues to each member, in starting the meeting at $7: 30$ one week rather than the usual 8:00. Now the crucial question is this: from the mere fact that it is in the interest of every member of the club to make a contract with every other member to meet at $7: 30$, does it follow - as Grice would have us believe - that each member of the group has an abstract obligation (or, indeed, a reason) to show up at 7:30? Says Kalin:

... no one yet has an obligation, or even a reason, to come at $7: 30$. No one can yet be blamed (or penalized) for arriving at $7: 55$, even if everyone else came a half-hour earlier. The moral obligation to be there comes into existence only at the time a new agreement is actually made... (Kalin, 1976, pp. 117-8).

Philosophical Studies 44 (1983) 115-120. 0031-8116/83/0441-0115\$00.60

Copyright (C) 1983 by D. Reidel Publishing Company, Dordrecht, Holland and Boston, U.S.A. 


\section{GRICE'S REPLY}

In replying to Kalin, Grice sets aside the dispute over the existence of an abstract obligation in favor of arguing that there is a reason for each member of the bowling club to come at 7:30 if the contract ground is true. Henceforth, we shall think of the Contract Ground Thesis as purged of the claim of abstract obligation.

Grice's strategy is to show that the Contract Ground is not true of the bowling club in the case described by Kalin, and when alterations are made to make it true, each member of the club does have a reason to arrive at 7:30. Kalin has, Grice would say, underestimated what must be shown to establish that the contract ground is true. To see this, consider the following propositions which refer to a situation involving two people, $A$ and $B$, and an action type $X$ :

CG: (The Contract Ground) It is in the interest of $A$ and $B$ to make with each other a contract to do $X$.

AC: $\quad$ (The Advantage Clause) It is advantageous for $A$ and $B$ to do $X$. .

RC: $\quad$ (The Reciprocity Clause) $A$ will do $X$ if $B$ does and $B$ will do $X$ if $A$ does.

Grice charges that Kalin assumes that the advantage clause is sufficient for the Contract Ground. But, Grice argues, this cannot be true because the reciprocity clause is a necessary condition for the contract ground and the advantage clause is not sufficient for the reciprocity clause. Thus, the advantage clause does not imply the Contract Ground. Grice offers (1977, p. 271) the following version of this argument for the Contract Ground Thesis which, he claims, shows why the thesis is immune to Kalinesque counterexamples:

(1) 'CG' strictly implies 'AC'.

(2) 'CG' strictly implies 'RC'.

(3) 'AC and RC' strictly implies that there is a reason for $A$ and $B$ to do $\boldsymbol{X}$.

Therefore,

(4) 'CG' strictly implies that there is a reason for $A$ and $B$ to do $X$ (i.e., the Contract Ground Thesis is true).

Counterexamples to (1) leap to mind. It may be in $A$ 's and $B$ 's interest to 
make a contract in order to be able to sue the other for not fulfilling his part. Other counterexamples are easily concocted. Grice, well aware of this, chooses to recast the Contract Ground. Modified, it reads:

CG*: It is in the interest of $A$ and $B$ to make with the other, and each with purposes that include the standard purpose, a contract to do $X$ (1977, p. 273).

$A$ makes a contract with $B$ do do $X$ with purposes which include the standard purpose if and only if one of $A$ 's purposes in making the contract is to get $B$ to do $X$ (p. 273). With this emendation, the argument proceeds as follows:

(1*) 'CG*' strictly implies 'AC'.

(2*) 'CG*' strictly implies ' $R C$ '.

(3*) 'AC and RC' strictly implies that there is a reason for $A$ and $B$ to do $X$ (unchanged).

Therefore,

(4*) 'CG*' strictly implies that there is a reason for $A$ and $B$ to $\operatorname{do} X$ (i.e., a modified version of the Contract Ground Thesis is true).

\section{QUICKSAN D}

Grice's argument fails; the failure is overdetermined. Both $\left(1^{*}\right)$ and $\left(2^{*}\right)$ are false.

Consider $\left(1^{*}\right)$. The very problems which forced the move from CG to CG* plague $\mathrm{CG}^{*}$. The reason for this is simple. Though $\mathrm{CG}^{*}$ requires that $A$ and $B$ have purposes which include the standard purpose, it doesn't guarantee that the reason that making a contract would be in their interest is that it would accomplish (this aspect of) their purpose. Thus, it may be in their interest for what we might call a 'non-standard reason' - for example, to appear to be conciliatory, to obtain an inheritance which is contingent upon them making an agreement, etc. This may be the only reason for which making the contract is in each of their interest. It is certainly compatible with this that each has, as a part of his purpose (indeed, it might be each person's sole purpose), the goal of getting the other to perform as the contract requires. But, of course, all this is compatible with it being disadvantageous to each of them for both of them to act as the contract stipulates. 
Imagine that two brothers, Abel and Baker, have been feuding since childhood. Each is now the head of a major oil company. Their aging mother, distressed by the enmity between her sons makes as a condition upon each receiving a share of the multibillion dollar estate that they sign a contract to work together in exploiting some off-shore oil fields to which the family has mineral rights. It is because of the inheritance each stands to acquire - and we may suppose only because of this - that it is in their interest to make a contract with each other to do this. (Perhaps actual exploitation of the oil fields would be economically unsound.) But suppose that Abel and Baker do not know about this condition upon their inheritance. They have, of late, both come to regret the emotional gulf between them and are willing to cooperate to overcome it. Both sons have information (mis)leading them to believe that exploitation of the off-shore oil fields would be economically profitable. Because of this perceived economic advantage of the mutual exploitation, Abel and Baker make a contract with each other with (we can suppose) the sole purpose of ensuring that the other plays his part in the venture.

Here, we have a situation in which it is in the interest of both Abel and Baker to make a contract with the other to work together to exploit the oil fields. Each has the standard purpose. But, not only would it not be to their advantage to abide by the terms of the contract, it would be disadvantageous for them to. $\left(1^{*}\right)$ is false.

Perhaps CG* could be further modified in such a way that these problems are avoided. But we shall not pursue this line further, for the problems with $\left(2^{*}\right)$ seem to vitiate the argument, making misguided any rescue effort for (1*).

Grice does not offer $\left(2^{*}\right)$ without justification. He argues for it as follows:

That this [RC] is a necessary condition [for CG*] is readily seen by supposing that it is not the case that $A$ will turn up if $B$ does. Then it is obviously not the case that it is in $B$ 's interest to make a contract with $A$. And if it is not the case that $B$ will turn up if $A$ does, then it is obviously not the case that it is in $A$ 's interest to make a contract with $B$ (1977, p. 270).

Grice is claiming, then, that the contrapositive of $\left(2^{*}\right)$ is incontrovertible. Indeed, at one point, he throws down the gauntlet for Kalin:

... [Kalin] has to show that an apparently obvious truth is false, the truth namely that if it is not the case that $A$ will turn up if $B$ does and not the case that $B$ will turn up if $A$ does, then it is not in their interest to make a contract $(1977$, p. 272). 
Whatever plausibility this argument has rests on the vagueness of the conditionals of RC.

Note that the conditionals cannot be interpreted as material conditionals. This is for two reasons. First, understood materially, RC (in conjunction with AC) will not imply that $A$ and $B$ have a reason to do $X$. Suppose that the advantage clause holds and, furthermore, it is in fact true that $A$ and $B$ both do $X$. $A$ may still have no reason to do $X$ because it is also true that $B$ would do $X$ regardless of what $A$ does. Thus, if $A$ has no reason to do $X$ other than getting $B$ to do $X, A$ has no reason to do $X$. Secondly, understood materially, the reciprocity clause does not follow from the contract ground. Suppose that $A$ does $X$ and $B$ doesn't; thus, on a material reading of RC, it is false. It may still be in the interest of $A$ and $B$ to make a contract to do $X$ because it may be that $B$ would do $X$ if he had made a contract to do so. Hence the contract may be effective in coordinating action. (More on this, momentarily.)

Both of these points suggest that the conditionals are to be interpreted as subjunctives. Suppose we interpret them in that way. RC is to be understood as:

$$
(A \square \rightarrow B) \&(B \square \rightarrow A)
$$

(where $A={ }_{\mathrm{df}} A$ will do $X ; B={ }_{\mathrm{df}} B$ will do $X$; and ' $\square \rightarrow$ ' indicates a subjunctive conditional). Now consider the contrapositive of (2*):

$$
\sim(A \square \rightarrow B) \vee \sim(B \square \rightarrow A) \rightarrow \sim \mathrm{CG}^{*} .
$$

Is this true? No. For the antecedent of (6) (i.e., the denial of the reciprocity clause) is compatible with:

$$
[(A \& C) \square \rightarrow B] \&[(B \& C) \square \rightarrow A]
$$

(where $C={ }_{\mathrm{df}} A$ and $B$ have a contract to do $X$ ). And the conjunction of (7) and the antecedent of (6) is consistent with:

$$
\sim[(A \& \sim C) \square \rightarrow B] \& \sim[(B \& \sim C) \square \rightarrow A] .
$$

But (7) and (8) together imply that if the advantage clause is true and $A$ and $B$ have purposes including the standard purpose, then $\mathrm{CG}^{*}$ is true. But since the antecedent of (6) is compatible with (7), (8), AC, and the statement about standard purposes, it cannot imply the falsity of CG*. Therefore, (6) is false.

Put a bit more intuitively, the challenge Grice offers is easily met. RC may 
be false and yet it is true that the existence of a contract alters the situation. Thus, were there a contract between $A$ and $B$ requiring each to do $X$, then each would do $X$ if the other were to do $X .^{5}$ So if each aims at getting the other to do $X$ and it is to the advantage of each that they both do $X$, it is in each of their interests to make a contract that each do $X$. And this is true even though, absent a contract, if one were to do $X$ the other would not.

This problem is neither superficial nor easily remediable. If some sort of reciprocity clause is required to make the modified Contract Ground (CG*) true, it will be (7) or a variant thereof. (Actually, if there is some cost attached to the making of the contract, (7) wouldn't be sufficient. We would have to know also that the contract made a difference - i.e., that something like (8) is true - and then the benefits of both people doing $X$ would have to be weighed against the costs of making the contract.) But, of course, the truth of (7) and whatever else is required to show the truth of CG* is quite compatible with the denial of (5). And it is the truth of (5) that Grice needs, to show that $A$ and $B$ have a reason to do $X$.

We think, then, that Kalin is right. The actual existence of the contract makes all the difference in whether there is an abstract obligation to perform the act in question. And, in light of the argument above, the actual existence of a contract can make all the difference in whether there is a reason for each member of the group to perform that act.

\section{The Ohio State University}

\section{NOTES}

1 Geoffrey Russell Grice: 1967, The Grounds of Moral Judgment (Cambridge University Press, London).

2 G. R. Grice: 1977, 'The contract ground: a reply to Jesse Kalin', Philosophical Studies 32, pp. 269-282.

3 Jesse Kalin: 1976, 'Grice's contract ground and moral obligation: the inadequacy of contractualism', Philosophical Studies 29, pp. 115-128.

4 G. R. Grice: 'The contract ground: a reply to Jesse Kalin', op cit.

s Strictly speaking, this does not say what we want to say here. The requisite claim is: If $A$ were to do $X$ and $A$ and $B$ had a contract to do $X$ then $B$ would do $X$ and if $B$ were to do $X$ and $A$ and $B$ had a contract to do $X$ then $A$ would do $X$. This differs from what is stated in the text because exportation fails for subjunctive conditionals. The differences do not affect the argument. 